\title{
Editorial
}

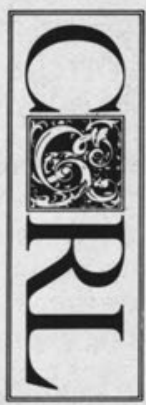

\section{What Is Research?}

What is research? One campus within the California State University defines it as "the disciplined quest for human understanding." There are many other definitions. Each subject field seems to have its own unique approach to examining problems.

As a doctoral student in librarianship at Berkeley I learned that the basic structure of research consists of (1) a statement of the problem, (2) the setting of hypotheses, (3) the development of a methodology, (4) the conduct of the study, (5) the findings of the study, (6) the analysis of findings, and (7) the conclusions. Beware the consequences if your conclusions went beyond your data.

Indeed, the provision of data is often the primary product of research. Critical thinking in a broad sense, meaningfulness, and utility are not relevant issues in far too many situations. There are many incentives to focus narrowly and to manage one's research efficiently. For doctoral students this habit of the mind is practical; that is, one is more likely to finish the thesis. But, in my opinion, a side effect of this approach is that the most significant and relevant research questions are avoided.

In this editorial I would like to discuss briefly the significance aspect of research and the context of research, or one might say, its politics.

Research is in fashion. Thousands of undergraduates approach our reference desks each day announcing that they need assistance in completing their research assignments for class the next day. For many students research is something that can be completed with the speed of summer lightning. The net result is that research is frequently viewed as mere technique or as something amorphous and all-encompassing. For the pure researcher, however, research may be thought of as a way to look at the world more clearly and with greater insight. Unfortunately, the accumulation of research in all its various manifestations leads to clutter. The key thinkers are able to pick their way through. For the rest of us the clutter may impede clarity and insight.

If data are the major de facto products of a significant number of research efforts, then a new orientation or approach to research may be needed. In a very general way the results of research should enlighten the reader. For most applied research it may be hoped that action to correct a problem situation would be an indirect benefit in as many cases as possible. Many manuscripts that come to College \& Research LIbraries, however, are simply collections of data. A survey is conducted and the data are presented. This is not enough.

The referees who review the manuscripts ask questions such as Is the research issue significant? Are there any significant findings? Does the research add anything new to our current store of knowledge? Does the author present the results of other studies on the same topic? Does the research build upon other research on the same topic? Does the author provide any information, guidelines, or recommendations that might reasonably allow the reader to do something different, in an improved way, because of having read the article? And finally, What difference does the article make; that is, if the manuscript is not published would something of value be lost? 
Critical thinking is central to most scholarly activity. It is also a key attribute of good research. The collection of data and adherence to a research method alone do not satisfy the critical thinking criterion. A scholarly article on an important issue that demonstrates the author's critical thinking is more interesting to many readers than a research-based study that presents data but no other evidence of the author's intellectual abilities, failing to satisfy the "so what" criterion.

My bias is toward robust scholarship. Take a meaty issue. Take an issue that has broad implications for the profession. Challenge yourself with its breadth. Overcome it through persistence. This is not the manager's approach. It is the approach of those who see something wrong and want to correct it. It is the approach of those who see research and publication as a means to improve the human condition through the context of librarianship. It is not research for its own sake to satisfy the criteria of graduation or promotion set by someone else. It is your own urge to know, to be right in the best sense of the word, and to help others through this knowledge.

In a future editorial I will discuss the profession's progress toward developing a set of important research questions. The questions developed by groups such as the Association of Research Libraries and the Council on Library Resources are frequently robust and with practical import for the profession and our clients. Likewise, the adoption of a statement, "Mission, Priority Areas, Goals," by the American Library Association at its 1986 Annual Conference, and the issuance of the strategic long-range "Planning Document: Goals and Strategies" provide the library community with the outline of a research agenda.

The content of research and how it is conducted are complicated subjects. Another interesting subject is the context of research. Research dollars are a closely guarded treasure and behind-the-scenes wars are fought to protect outside sources of funding. Recently, the nineteen-campus California State University (CSU) system attempted to expand its research role and to offer stand-alone doctorates. Approval was sought from the state for an expanded research mission. This interest brought the system up against the interests of the University of California (UC). It was viewed by some as a classic zero-sum situation in which the dollars to fund an expansion of the CSU research would reduce the research dollars available to UC.

The "expanded research mission" issue faced by many if not all of the nation's 601 comprehensive universities was addressed by Philip H. Abelson in a Science editorial (February 12). Limited institutional funds for equipment, supplies, and travel, as well as limited opportunities for obtaining federal grants are cited as important deficiencies. Abelson concludes,

In pursuing their goal to integrate research and teaching more effectively, the comprehensive universities are on the right track. Their cause merits support.

Some of my colleagues at non-ARL institutions have suggested that they face similar frustrations when trying to compete with "research" libraries for grant funds.

Another interesting context issue at comprehensive universities is that many of the faculty view themselves as teachers and not researchers. To move toward an expanded research orientation university administrators may have to do so over many strong objections. To facilitate this movement the definitions of what is research are moderated so that the interests of faculty are more easily accommodated. This evenhanded approach has won over many otherwise reluctant faculty. It has also allowed the debate about the appropriate research mission for formerly small teachers' colleges to be conducted in a relatively calm and reasoned manner.

Many articles have appeared in library literature about the research and publishing obligations of librarians. In this sense our concerns and interests parallel those of many of the faculty at the comprehensive universities.

An award for the best CERL article in 1987 will be given in New Orleans to the authors of "Librarians and Faculty Members: Coping with Pressures to Publish" (November 1987). The authors state that "librarians' struggles with faculty status bring to mind an old maxim: happiness isn't so much getting what you want as wanting what you get." Many 
will find it reassuring to know that library and instructional faculty frequently have mixed feelings about their research and publishing responsibilities.

Many of us need to work together to put research in all its manifestations on the right track thereby justifying the commitment of others to what can be a rewarding venture. Maybe then we will want what we get.

\section{CHARLES MARTELL}

\section{United Nations Publications Books about Your World}

\section{General}

Yearbook of the United Nations

The principal reference work of the United Nations, providing in single annual volumes, a comprehensive account of the Organization's wide-ranging activities since 1946 .

Latest issue: 1983

E.86.1.1

(ISBN: 92-1-100312-1)

$\$ 85.00$ (Hard)

Everyone's United Nations

Official textbook which contains a definitive history of the Organization from 1946 to date.

Latest issue: 10 th ed

E. 86.1 .16

E.86.1.16

(ISBN: 92-1-100273-7)

(ISBN: 92-1-100274-5)

$\$ 14.95$ (Hard)

s 9.95 (Soft)

Directory of United Nations Databases and Information

\section{Systems}

A repertoire of over 600 information databases in 36 UN affiliated organiza. tions. It enables one to see what information and services are available in the United Nations family as a whole and how to obtain detailed information

from particular organizations.

GV.E. 84.0 .5

$\$ 35.00$

Reference

Demographic Yearbook

Covers data on population for more than 250 countries and areas. Annual since 1949.

Latest issue: 1986

E/F.87.XIII.1 (ISBN: 92-1-051071-2)

(ISBN: 92-1-051070-4)

$\$ 85.00$ (Soft) $\$ 110.00$ (Hard)

Yearbook of International Trade Statistics Annual since 1950

Latest issue: 1985 (2 Vols.)

EF.87.XVIL.3

(ISBN: 92-1-061119-5)
Energy Statistics Yearbook Provides a global framework of comparable data on trends and developments

in the supply of all forms of energy. Essential to study the outlook in the supply and demand of energy. Hardcover. Latest issue: 1985

EF.86.XVII.13 (ISBN: 92-1-061112-8)

$\$ 51.00$

Statistical Yearbook

Provides a wealth of data for more than 280 countries and territories on economic and social subjects such as population, agriculture, trade, national

income and many others. Annual since 1949.

Latest issue: 1985

E/F.86.XVII.1

(ISBN: 92-1-061105-5)

$\$ 85.00$ (Hard)

\section{Business/Economics}

\section{World Economic Survey}

Provides an overview of salient developments in the world economy. Attention is drawn to changes in international policies needed to improve the pace of development in developing countries. Annual since 1948. Latest issue: 1987

E.87.II.C.1

(ISBN: 92-1-109113-6)

$\$ 22.00$

To order publications, by title and sales number, contact your wholesaler or order direct. For more information write for our complete 1988 catalog at the address below. Publisher's ISBN prefix: (92-1).

\section{United Nations Publications}

Room DC2-853 - Department 0032

New York, NY 10017

Palais des Nations $\bullet 1211$ Geneva 10 . Switzerland 


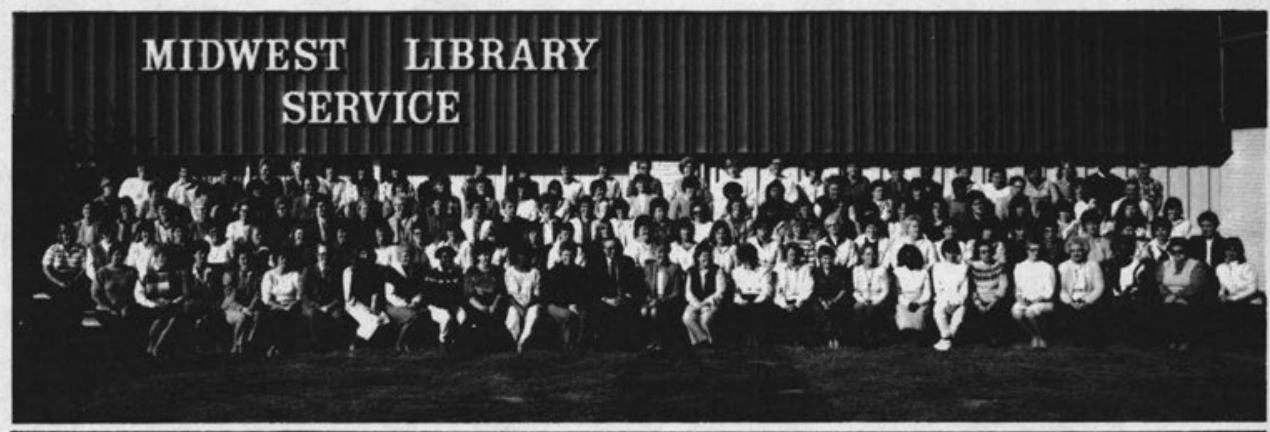

\section{MLS-160 People, 27 Years of Service to Libraries}

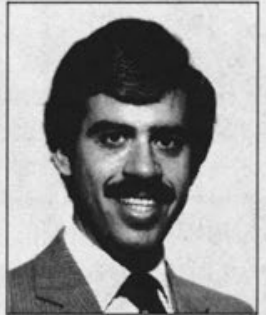

Jay Askuvich General Sales Manager

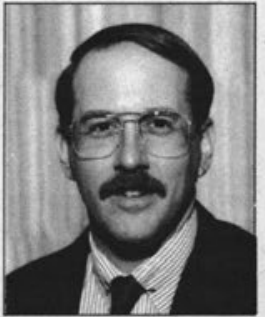

Scott Schmidt Midwest

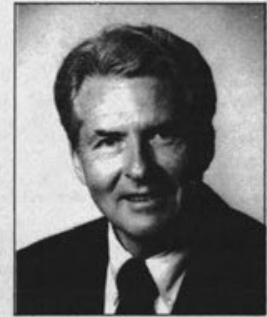

Carl Dorr

Southeast

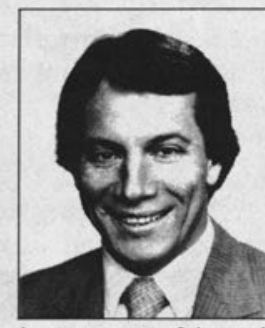

Lawrence Nagel West

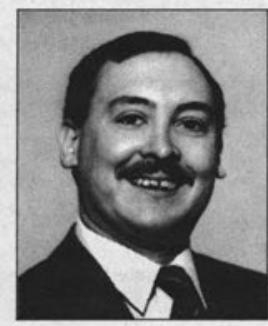

Forrest Link Northeast

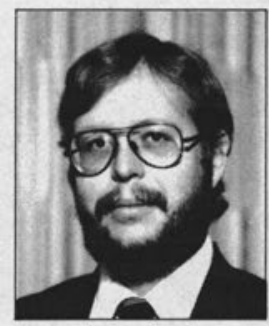

Kim Anderson Mountain Plains



Lorraine Best Canada

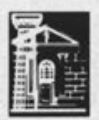

Midwest Library Service

11443 St. Charles Rock Road Bridgeton, MO 63044, USA

Call toll-free 1-800-325-8833

Missouri librarians call toll-free 1-800-392-5024

Canadian librarians call toll-free 1-800-527-1659 